\title{
BCG is a Good Immunotherapeutic Agent for Viral and Autoimmune Diseases: Is it a New Weapon against Coronavirus (COVID-19)?
}

\author{
Inas K. Sharquie ${ }^{1 \star}$
}

\begin{abstract}
${ }^{1}$ Associate Professor of Immunology, Ph.D. Department of Microbiology \& Immunology, College of Medicine, University of Baghdad, Baghdad, IRAQ
\end{abstract} *Corresponding Author: iksharquie@yahoo.com

Citation: Sharquie IK. BCG is a Good Immunotherapeutic Agent for Viral and Autoimmune Diseases: Is it a New Weapon against Coronavirus (COVID-19)?. Electron J Gen Med. 2020;17(6):em229. https://doi.org/10.29333/ejgm/7892

ARTICLE INFO
Received: 2 Apr. 2020
Accepted: 4 Apr. 2020

\begin{abstract}
Now nearly a century old, the Bacillus Calmette-Guérin (BCG) vaccine is used routinely in humans for the prophylaxis of tuberculosis and to clear up leprosy. As the immune response to the vaccine shows some degree of cross-antigenicity, the vaccine also affects a level of resistance to a range of unrelated diseases and pathogens.

Clinical studies data have shown that the BCG vaccine has effects on autoimmune and inflammatory diseases.

Although the vaccine does not possess any inherent antiviral activity, it engages in the host immune system such that many types of viral infections are considerably reduced. Hence, we expect that the frequency and severity of many microbial diseases, including COVID-19, will be lower in counties in which mass BCG vaccination programs are implemented. So the BCG vaccine may prove useful in the coming months especially in countries where already have mass BCG vaccination, as the COVID-19 pandemic has placed an unprecedented strain on health services across the world. Currently, countless front-line healthcare staff is in immediate danger of exposure to the SARS-CoV-2 virus.

Furthermore, as oral zinc sulfate as immunomodulator has proved an effective means to treat various viral diseases (including viral warts and herpes), parasitic infections, and diseases with autoimmune reactions such as Behcet's disease and recurrent aphthous stomatitis, it could be employed in combination with the BCG vaccine to enhance the immunological functions of patients with COVID-19. So BCG immunotherapy combined with oral zinc sulfate will be encouraging protective programs in societies where coronavirus is going to spread.
\end{abstract}

Keywords: BCG, Coronavirus, COVID-19, Zinc sulfate

\section{INTRODUCTION}

The Bacillus Calmette-Guérin (BCG) vaccine was developed in the early part of the $20^{\text {th }}$ Century by Albert Calmette and Camille Guérin. The process involved subculturing different strains of Mycobacterium tuberculosis and M. bovis (with each subculture, the strains produced become progressively less virulent). Work started in 1908 and lasted 13 years, during which time over 200 subcultures of $M$. bovis were produced. In 1921 , the BCG vaccine was used in humans for the first time (1).

The principal use of the BCG vaccine is to protect against tuberculosis, although it is far from perfect in this regard. The vaccine is thought to reduce the risk of contracting tuberculosis by approximately $50 \%$, although this number varies by population (e.g. while the UK exhibits a protective effect of between $60 \%$ and $80 \%$, the vaccine's protective effect drops to nearly $0 \%$ in equatorial countries) $(2,3)$.

However, despite the benefits of the BCG vaccine, a recent meta-analysis determined that the vaccine has the potential to increase the risk of developing non-Hodgkin's lymphoma (4). Having said that, Salmon et al. noted that, after restricting their data analysis solely to higher-quality studies, the BCG vaccine was no longer associated with an increased risk of nonHodgkin's lymphoma.

The BCG vaccine has also been used as an immunotherapeutic agent in the treatment of superficial bladder cancer, although there is some considerable risk to the procedure, specifically in terms of toxicity and non-response $(5,6)$. There is also some evidence to demonstrate BCG-based efficacy in patients with type I diabetes, as the vaccine has been linked to reduced blood sugars (resulting in accelerated glucose utilisation), changes in metabolism, and epigenetic changes in T regulatory genes (7).

\section{BCG AND TUBERCULOSIS}

Initially, the public uptake of the BCG vaccine was slow. A contaminated batch of the vaccine caused 72 infant mortalities and led to intense public criticism and legal action against the vaccine's manufacturers. Now reasonably well-known, the socalled "Lübeck Disaster" involved the inoculation of 251 neonates between 1929 and 1933, of whom 173 went on to develop symptoms of tuberculosis infection as a result of vaccines being contaminated with live Mycobacterium tuberculosis (8). 
Although the standard delivery of the BCG vaccine is by mouth, recent research in rhesus macaques has indicated that there may be improved protection when the vaccine is delivered intravenously $(9,10)$.

Following the somewhat understandable hesitancy of the public to engage with the vaccine following the Lübeck Disaster, BCG vaccine usage did not expand until after World War II.

The diagnostic test for tuberculosis, the Mantoux test, makes use of a combination of proteins known as tuberculin, which is a glycerol extract from the bacterium. The protein is injected intradermally, and the result of the test is read 48 to 72 hours later. Patients who have been infected mount a type IV hypersensitivity reaction, recruiting $T$ cells to the area and generating local inflammation (11). A recent study has posited that a granulomatous reaction might appear at the site of the tuberculin injection, and that, simulating TB pathology, this severe reaction might be of value to TB diagnosis (12).

Currently, the BCG vaccine is not universally administered. Some countries choose instead to detect active disease via the Mantoux tests and treat cases as they arise.

\section{BCG AND LEPROSY}

Leprosy is another disease caused by bacteria of the genus Mycobacterium. As mentioned previously, there is some considerable variation in the level of protection offered by the BCG vaccine against tuberculosis. However, a study in Malawi noted that, whilst levels of protection against tuberculosis were minimal, the BCG vaccine offered some protection against $M$. leprae infection (13). A meta-analysis incorporating 26 studies concluded that, although insufficient to protect against tuberculosis, a single dose of BCG is capable of preventing leprosy (14). A second dose generated even further protection, and was recommended for contacts of leprosy patients.

\section{BCG AND AUTOIMMUNE DISEASES}

The BCG vaccine has shown promise in terms of its potential application to conditions other than mycobacterial infections, specifically autoimmune disorders. There is thought to be some degree of cross-antigenicity between mycobacterial and human antigens (15). Indeed, the BCG vaccine has been shown to be of some benefit to the treatment of high-risk superficial bladder carcinoma (although such treatment can result in severe complications, including reactive arthralgia or arthritis) (16). Radiographic evaluations of this reactive arthritis often reveal no abnormal findings, and laboratory testing yields only non-specific inflammatory markers. There are also isolated case reports of autoimmune retinopathy associated with intravesical BCG (17).

In contrast to the induction of autoimmune conditions, in some cases BCG has exhibited some protective effects against inflammatory and autoimmune diseases. Murine studies have shown the vaccine to be of some benefit against allergic asthma, multiple sclerosis, and type I diabetes (as mentioned previously) (18).

Alopecia areata is thought to be an autoimmune disease that is precipitated by the compromise of hair follicles that are usually immune-privileged (19). Standard treatments involve topical corticosteroids, minoxidil, or ciclosporin (although the efficacy of such treatments is questionable) (20). A study from 2003 provides evidence that BCG immunotherapy is an effective treatment for alopecia areata (especially severe cases), and that the BCG vaccine can be used either alone or in combination with other treatments in such contexts (21). Oral zinc sulphate (employed as an immunomodulator) is another effective therapeutic action for alopecia areata.

A study from 2010 indicates that, when injected locally, BCG-polysaccharide nucleic acid, used in combination with prednisolone acetate, is of some benefit to the treatment of alopecia areata (22). However, this was a very small-scale study, and there have been no further publications on the matter.

BCG polysaccharide nucleic acids are also employed in the management of both oral and cutaneous lichen planus, a chronic immune-mediated inflammatory condition that can affect the hair, nails, skin, and mucous membranes (23). Although this result was presented by another small study, statistically significant differences were identified that indicated a positive response from participants with alopecia areata that were treated with BCG.

\section{BCG AND ORAL APHTHOSIS}

Aphthous ulcers form in the membranes of the mouth and produce painful (although benign and non-contagious) lesions. Although their pathophysiology is not completely understood, T-cell responses are thought to be involved. Such responses may be triggered by a variety of pathological or environmental reasons (24). Other inflammatory or autoimmune conditions can also trigger persistent aphthous ulcers, particularly conditions affecting the gastrointestinal tract, such as inflammatory bowel diseases (25).

The application of three intradermal BCG injections at monthly intervals has shown some promise in the management of recurrent oral aphthosis over a six month follow-up period (26). Conversely, however, a Crohn's diseaselike gastrointestinal inflammatory disease has been observed to arise shortly after the intravesical injection of BCG, suggesting the possibility of increased immune and inflammatory activity in the gastrointestinal tract (27). This induction of Crohn's disease-like symptoms via the administration of BCG would tie in with the body of literature that suggests a mycobacterial causative agent: the Mycobacterium avium subspecies paratuberculosis has been implicated as a cause of not only Crohn's disease and ulcerative colitis, but also colorectal cancer $(28,29)$.

\section{BCG AND VIRAL INFECTION}

\section{Viral Warts}

Given its capacity to mobilise the immune system, it follows that administration of BCG may aid in the management of infections. Indeed, there is some accumulated evidence that the $B C G$ vaccine offers non-specific protection and reduces the morbidity and mortality rates of viral infections (30). Viral warts, for example, have been managed using intradermal injections of BCG (intradermal injection of saline were used as 
a control). The resulting response rate was a little over $40 \%$ (31). Interestingly, tuberculin (the antigenic extract of $M$. tuberculosis) has been injected intralesionally for warts, and had shown some efficacy as an immunotherapy for viral warts (32).

\section{Herpes Simplex Virus Infection}

Similarly to viral warts, BCG has shown some effect in the context of herpes infections. Early studies evidenced no effect (33), or even some level of toxicity, upon repeated exposure (34). However, a larger, later study indicated that, although there is indeed some preventative effect of BCG on herpes simplex recurrences, this effect drops over time $(19 \%$ of patients were herpes-free after three years, and $9 \%$ after six years) (35).

\section{Coronavirus: Is BCG beneficial for coronaviruses?}

The SARS-CoV-2 virus has swept across the globe at what for some might consider a startling speed, but is essentially in accord with mathematical pandemic models (36-38).

Given the virulence of this particular virus, and the severity of the COVID-19 respiratory syndrome that accompanies many incidences of infection, any protective strategy is of substantial potential benefit.

As the COVID-19 pandemic is still only in its first few months, peer-reviewed data is scarce. Having said that, there are some useful trends that have been identified in the existing data, and unreviewed studies are available on various pre-print servers (39).

There is the known effect of trained immunity, in which infection with one pathogen confers protection against other pathogens. This effect has been mentioned briefly with respect to the capacity of the BCG inoculation to render the immune system prepared for viral infections $(30,40)$.

As the BCG vaccine is already approved for human use, any human studies to determine efficacy would only require Phase III clinical trials, making this an attractive option (foregoing Phase I and II trials can take a year off the development time of a vaccine). Indeed, the Abundance Foundation is currently funding such a clinical trial (41).

There is substantial data to indicate that BCG vaccination provides protection against a range of infections, not simply the mycobacterium for which the vaccine was originally developed. A study that involved both BCG vaccination at birth and delayed vaccination evidenced that the reduced mortality rate of the vaccinated group was attributable to the BCG-based prevention of a range of conditions, including respiratory infections, neonatal sepsis, and fevers (30). Similarly, BCG vaccination of elderly patients over a period of three months was observed to result in a reduction in the incidence of acute upper respiratory tract infections (42).

In addition to its capacity to increase host resistance to non-specific infections, BCG has also shown some promise as a non-specific immunotherapy for virus-mediated conditions, including viral warts and herpes simplex (as described above).

Interestingly, the BCG vaccine can also improve the immune response to other vaccines. One study involving the administration of the BCG vaccine prior to the influenza vaccine showed that antibody titre to the latter was significantly enhanced (43). This study also evidenced that following the BCG vaccination, there was a more rapid seroconversion and enhanced pro-inflammatory leukocyte response, and even a modulation of cytokine responses against unrelated pathogens.

\section{ZINC, INFECTION AND IMMUNITY}

Zinc is essential to the health of human beings. Zinc is involved in the metabolism of more 300 enzymes in the body (44), and has many essential functions, including maintaining the proper reproductive function, immune status, wound repair, macrophage and neutrophil functions, natural killer cell activity, and complement activity (44). Zinc deficiency might be associated with many metabolic and dermatological manifestations, but most importantly zinc deficiency interferes with immunological functions (45).

A number of studies have treat various medical problems via the use of oral zinc sulfate (including viral warts (46), herpes simples infections (47), and acute cutaneous leishmaniasis) (48-50). Zinc sulfate is also used as a therapy for autoimmune diseases like alopecia areata (51), Behcet's disease (52), and recurrent aphthous stomatitis (53). Hence, we suggest that oral zinc sulfate be used to protect human beings from infections like COVID-19. Also, we can suggest using oral zinc in combination with BCG vaccine to have much more effective protection against infections including COVID-19.

\section{CONCLUSION}

The effects of the BCG vaccine have been studied for close to a century, and although its efficacy in the prevention of paediatric tuberculosis is highly variable, likely as a function of genetic and environmental factors, the vaccine has demonstrated some success in other areas as its capacity to ward off leprosy is well documented, as it its function in nonspecific immunity.

Given the impact that it is known to have in reducing the incidence of respiratory viral infections, its use during the COVID-19 pandemic may prove beneficial. Results of upcoming clinical trials are eagerly anticipated and encouraging. We also can conclude that societies that have received BCG as a mass vaccination will have less frequency of COVID-19 and might run a mild course of the disease. We also can recommend using oral zinc sulfate combined with BCG immunotherapy to have more effective protection against infection including COVID-19 than BCG immunotherapy alone. BCG vaccine has much more rapid action in people who have already been BCG vaccinated. Hence societies with mass vaccination will have more quick and powerful action in protection against coronavirus.

\section{REFERENCES}

1. Fine PEM, Carneiro IAM, Milstien JB, Clements CJ, World Health $O$. Issues relating to the use of BCG in immunization programmes: a discussion document. Geneva: World Health Organization; 1999. Available at: https://apps.who.int/iris/handle/10665/66120

2. Colditz GA, Brewer TF, Berkey CS, Wilson ME, Burdick E, Fineberg HV, et al. Efficacy of BCG vaccine in the prevention of tuberculosis. Meta-analysis of the published literature. JAMA. 1994;271(9):698-702. https://doi.org/10.1001/ jama.1994.03510330076038 PMID:8309034 
3. Fine PE. Variation in protection by BCG: implications of and for heterologous immunity. Lancet. 1995;346(8986):133945. https://doi.org/10.1016/s0140-6736(95)92348-9 PMID:7475776

4. Salmon C, Conus F, Parent M-É, Benedetti A, Rousseau M-C. Association between Bacillus Calmette-Guerin (BCG) vaccination and lymphoma risk: A systematic review and meta-analysis. Cancer Epidemiology. 2020;65:101696. https://doi.org/10.1016/j.canep.2020.101696

5. Houghton BB, Chalasani V, Hayne D, Grimison P, Brown CSB, Patel MI, et al. Intravesical chemotherapy plus bacille Calmette-Guérin in non-muscle invasive bladder cancer: a systematic review with meta-analysis. BJU International. 2013;111(6):977-83. https://doi.org/10.1111/j.1464-410X. 2012.11390.x PMID:23253618

6. Fuge O, Vasdev N, Allchorne P, Green JS. Immunotherapy for bladder cancer. Research and reports in urology. 2015;7:65-79. https://doi.org/10.2147/rru.s63447 PMID: 26000263

7. Kühtreiber WM, Tran L, Kim T, Dybala M, Nguyen B, Plager $\mathrm{S}$, et al. Long-term reduction in hyperglycemia in advanced type 1 diabetes: the value of induced aerobic glycolysis with BCG vaccinations. NPJ vaccines. 2018;3:23. https://doi.org/10.1038/s41541-018-0062-8 PMID:29951281

8. Fox GJ, Orlova M, Schurr E. Tuberculosis in Newborns: The Lessons of the "Lübeck Disaster" (1929-1933). PLOS Pathogens. 2016;12(1):e1005271. https://doi.org/10.1371/ journal.ppat.1005271

9. Behar SM, Sassetti C. Tuberculosis vaccine finds an improved route. Nature. 2020;577(7788):31-2. https://doi.org/10.1038/d41586-019-03597-y PMID:31894152

10. Darrah PA, Zeppa JJ, Maiello P, Hackney JA, Wadsworth $\mathrm{MH}, 2$ nd, Hughes TK, et al. Prevention of tuberculosis in macaques after intravenous BCG immunization. Nature. 2020;577(7788):95-102. https://doi.org/10.1038/s41586019-1817-8 PMID: 31894150

11. Vukmanovic-Stejic M, Reed JR, Lacy KE, Rustin MHA, Akbar AN. Mantoux Test as a model for a secondary immune response in humans. Immunology Letters. 2006;107(2):93101. https://doi.org/10.1016/j.imlet.2006.08.002 PMID: 16979761

12. Sharquie KE, Noaimi AA, Khalaf FA. Granulomatous Reaction at the Site of Positive Tuberculin Skin Test is a Marker of Active TB (Clinical and Histopathological Study). American Journal of Dermatology and Venereology. 2019;8(4):55-60.

https://doi.org/10.5923/j.ajdv.20190804.01

13. Karonga Prevention Trial Group. Randomised controlled trial of single BCG, repeated BCG, or combined BCG and killed Mycobacterium leprae vaccine for prevention of leprosy and tuberculosis in Malawi. Lancet. 1996;348(9019):17-24. https://doi.org/10.1016/S0140-6736 (96)02166-6 PMID:8691924

14. Setia MS, Steinmaus C, Ho CS, Rutherford GW. The role of BCG in prevention of leprosy: a meta-analysis. Lancet Infect Dis. 2006;6(3):162-70. https://doi.org/10.1016/S1473-3099 (06)70412-1 PMID:16500597

15. Thorns CJ, Morris JA. Common epitopes between mycobacterial and certain host tissue antigens. Clinical and experimental immunology. 1985;61(2):323-8. https://www.ncbi.nlm.nih.gov/pmc/articles/PMC1577309 PMID:2412744
16. Tinazzi E, Ficarra V, Simeoni S, Artibani W, Lunardi C. Reactive arthritis following BCG immunotherapy for urinary bladder carcinoma: a systematic review. Rheumatology International. 2006;26(6):481-8. https://doi.org/10.1007/s00296-005-0059-2 PMID:16220289

17. Sharan S, Thirkill CE, Grigg JR. Autoimmune retinopathy associated with intravesical BCG therapy. The British journal of ophthalmology. 2005;89(7):927-8. https://doi.org/10.1136/bjo.2004.065359 PMID:15965187

18. Kowalewicz-Kulbat M, Locht C. BCG and protection against inflammatory and auto-immune diseases. Expert Review of Vaccines. 2017;16(7):699-708. https://doi.org/10.1080/ 14760584.2017 .1333906

19. Rajabi F, Drake LA, Senna MM, Rezaei N. Alopecia areata: a review of disease pathogenesis. British Journal of Dermatology. 2018;179(5):1033-48. https://doi.org/10.1111 /bjd.16808 PMID:29791718

20. Delamere FM, Sladden MJ, Dobbins HM, Leonardi - Bee J. Interventions for alopecia areata. Cochrane Database of Systematic Reviews. 2008(2). https://doi.org/10.1002/ 14651858.CD004413.pub2 PMID:18425901

21. Sharquie KE, Lafta RK, Al Samarrai A. BCG-immuno therapy in patients with alopecia areata. Yemeni Journal for Medical Sciences. 2003;3:15-9. Available at: https://vlibrary.emro.who.int/imemr/bcg-immunotherapy-in-patients-with-alopecia-areata/

22. Yan H-c. BCG-polysaccharide nucleic acid with prednisolone acetate in the treatment of alopecia areata Practical Journal of Clinical Medicine. 2010;2. Available at: http://en.cnki.com.cn/Article_en/CJFDTOTAL-YYLC201002 031.htm

23. Nasr MM, Ebrahim HM, Khattab FM, Marei AM. Bacillus Calmette-Guerin, polysaccharide nucleic acid in the treatment of cutaneous and oral lichen planus. Dermatologic Therapy. 2018;31(3):e12591. https://doi.org/ 10.1111/dth.12591 PMID:29405515

24. Giannetti L, Murri Dello Diago A, Lo Muzio L. Recurrent aphtous stomatitis. Minerva Stomatol. 2018;67(3):125-8. https://doi.org/10.23736/S0026-4970.18.04137-7 PMID:29332375

25. Mortada I, Leone A, Gerges Geagea A, Mortada R, Matar C, Rizzo M, et al. Oral manifestations of inflammatory bowel disease. J Biol Regul Homeost Agents. 2017;31(3):817-21. https://www.ncbi.nlm.nih.gov/pubmed/28958141 PMID:28958141

26. Sharquie KE, Hayani RK. BCG as a new therapeutic and prophylactic agent in patients with severe oral aphthosis. Clin Exp Rheumatol. 2005;23(6):914. Available at: http://www.ncbi.nlm.nih.gov/pubmed/16396718 PMID:16396718

27. Pizzi M, Albertoni L, Stefanizzi L, Mescoli C, Rugge M. Gastrointestinal Crohn-like disease following BCG therapy. International Journal of Colorectal Disease. 2015;30(12):1745-6. https://doi.org/10.1007/s00384-015-21 57-2 PMID:25690704

28. Pierce ES. Could Mycobacterium avium subspecies paratuberculosis cause Crohn's disease, ulcerative colitis...and colorectal cancer? Infectious agents and cancer. 2018;13:1. https://doi.org/10.1186/s13027-017-01 72-3 PMID:29308085 
29. Feller M, Huwiler K, Stephan R, Altpeter E, Shang A, Furrer $\mathrm{H}$, et al. Mycobacterium avium subspecies paratuberculosis and Crohn's disease: a systematic review and metaanalysis. Lancet Infect Dis. 2007;7(9):607-13. https://doi.org/10.1016/S1473-3099(07)70211-6 PMID:17714674

30. Moorlag SJCFM, Arts RJW, van Crevel R, Netea MG. Nonspecific effects of BCG vaccine on viral infections. Clinical Microbiology and Infection. 2019;25(12):1473-8. https://doi.org/10.1016/j.cmi.2019.04.020 PMID: 31055165

31. Sharquie KE, Al-Rawi JR, Al-Nuaimy AA, Radhy SH. Bacille Calmette-Guerin immunotherapy of viral warts. Saudi Med J. 2008;29(4):589-93. Available at: http://www.ncbi. nlm.nih.gov/pubmed/18382805 PMID:18382805

32. Sharquie KE, Al-Rawi J, Noaimi A, Majly W. Tuberculin as Intralesional Therapy for Viral Warts-Single-Blind, Split, Placebo, Controlled Study. Journal of Cosmetics, Dermatological Sciences and Applications. 2016;6:191-8. https://doi.org/10.4236/jcdsa.2016.65024

33. Bierman SM. BCG Immunoprophylaxis of Recurrent Herpes Progenitalis. Archives of Dermatology.1976;112(10):1410-5. https://doi.org/10.1001/archderm.1976.01630340028008 PMID:183605

34. Douglas JM, Vontver LA, Stamm WE, Reeves WC, Critchlow $C$, Remington $M L$, et al. Ineffectiveness and toxicity of BCG vaccine for the prevention of recurrent genital herpes. Antimicrobial agents and chemotherapy. 1985;27(2):203-6. https://doi.org/10.1128/aac.27.2.203 PMID:3885848

35. Hippmann G, Wekkeli M, Rosenkranz AR, et al. [Nonspecific immune stimulation with BCG in Herpes simplex recidivans. Follow-up 5 to 10 years after BCG vaccination]. Wien Klin Wochenschr. 1992;104(7):200-4. Available at: http://www.ncbi.nlm.nih.gov/pubmed/1523844 PMID:1523844

36. Simpson CR, Beever D, Challen K, De Angelis D, Fragaszy E, Goodacre S, et al. The UK's pandemic influenza research portfolio: a model for future research on emerging infections. Lancet Infect Dis. 2019;19(8):e295-e300. https://doi.org/10.1016/S1473-3099(18)30786-2 PMID:31006605

37. Panovska-Griffiths J, Grieco L, van Leeuwen E, Baguelin M, Pebody R, Utley M. Are we prepared for the next influenza pandemic? Lessons from modelling different preparedness policies against four pandemic scenarios. Journal of Theoretical Biology. 2019;481:223-32. https://doi.org/10.1016/j.jtbi.2019.05.003 PMID:31059716

38. Cakir Z, Savas HB. A Mathematical Modelling Approach in the Spread of the Novel 2019 Coronavirus SARS-CoV-2 (COVID-19) Pandemic. Electronic Journal of General Medicine. 2020;14(4). https://doi.org/10.29333/ejgm/7861

39. Miller A, Reandelar MJ, Fasciglione K, Roumenova V, Li Y, Otazu GH. Correlation between universal BCG vaccination policy and reduced morbidity and mortality for COVID-19: an epidemiological study. medRxiv. 2020: 2020.03.24.20042937. https://doi.org/10.1101/2020.03.24. 20042937

40. Arts RJW, Netea MG. Chapter 8 - Epigenetic Rewiring of Monocytes in BCG Vaccination. In: Faustman DL, editor. The Value of BCG and TNF in Autoimmunity (Second Edition): Academic Press; 2018. p. 109-20. https://doi.org/10.1016/B978-0-12-814603-3.00008-2
41. Abundance Foundation. Crucial research testing efficacy against COVID-19 of most widely used vaccine in the world| Abundance Foundation [Internet]. 2020. Available at: https://www.abundance.org/crucial-research-assessingefficacy-in-preventing-covid-19-of-widely-used-vaccinefor-tuberculosis-called-bcg/

42. Wardhana, Datau EA, Sultana A, Mandang VV, Jim E. The efficacy of Bacillus Calmette-Guerin vaccinations for the prevention of acute upper respiratory tract infection in the elderly. Acta Med Indones. 2011;43(3):185-90. Available at: http://www.ncbi.nlm.nih.gov/pubmed/21979284 PMID:21979284

43. Leentjens J, Kox M, Stokman R, Gerretsen J, Diavatopoulos $D A$, van Crevel $R$, et al. BCG Vaccination Enhances the Immunogenicity of Subsequent Influenza Vaccination in Healthy Volunteers: A Randomized, Placebo-Controlled Pilot Study. The Journal of Infectious Diseases. 2015;212(12):1930-8. https://doi.org/10.1093/infdis/jiv332 PMID:26071565

44. Bibi Nitzan Y, Cohen AD. Zinc in skin pathology and care. Journal of Dermatological Treatment. 2006;17(4):205-10. https://doi.org/10.1080/09546630600791434 PMID:16971312

45. Gupta M, Mahajan VK, Mehta KS, Chauhan PS. Zinc therapy in dermatology: a review. Dermatology research and practice. 2014;2014:709152-. https://doi.org/10.1155/ 2014/709152 PMID:25120566

46. Al-Gurairi FT, Al-Waiz M, Sharquie KE. Oral zinc sulphate in the treatment of recalcitrant viral warts: randomized placebo-controlled clinical trial. British Journal of Dermatology. 2002;146(3):423-31. https://doi.org/10.1046/ j.1365-2133.2002.04617.x PMID:11952542

47. Mahajan BB, Dhawan M, Singh R. Herpes genitalis - Topical zinc sulfate: An alternative therapeutic and modality. Indian journal of sexually transmitted diseases and AIDS. 2013;34(1):32-4. https://doi.org/10.4103/0253-7184.112867 PMID:23919052

48. Sharquie KE, Najim RA, Farjou IB, Al-Timimi DJ. Oral zinc sulphate in the treatment of acute cutaneous leishmaniasis. Clinical and Experimental Dermatology. 2001;26(1):21-6. https://doi.org/10.1046/j.1365-2230.2001. 00752.x PMID:11260171

49. Najim RA, Sharquie KE, Farjou IB. Zinc Sulphate in the Treatment of Cutaneous Leishmaniasis: an in Vitro and Animal Study. Memórias do Instituto Oswaldo Cruz. 1998;93:831-7. https://doi.org/10.1590/S0074-0276199800 0600025 PMID:9921312

50. Sharquie KE, Noaimi AA, Al-Salam WS. Treatment of Acute Cutaneous Leishmaniasis by Oral Zinc Sulfate and Oral Ketocanazole Singly and in Combination. Journal of Cosmetics, Dermatological Sciences and Applications. 2016;6(3):105-15. https://doi.org/10.4236/jcdsa.2016.63 014

51. Sharquie KE, Noaimi AA, Shwail ER. Oral Zinc Sulphate in Treatment of Alopecia Areata (Double Blind; CrossOver Study). Journal of Clinical \& Experimental Dermatology Research. 2012;3:150. https://doi.org/10.4172/21559554.1000150

52. Sharquie KE, Najim RA, AL-Dori WS, AL-Hayani RK. Oral zinc sulfate in the treatment of Behcet's disease: A double blind cross-over study. The Journal of Dermatology. 2006;33(8):541-6. https://doi.org/10.1111/j.1346-8138. 2006.00128.x PMID:16923135 
53. Sharquie KE, Najim RA, Al-Hayani RK, Al-Nuaimy AA, Maroof DM. The therapeutic and prophylactic role of oral zinc sulfate in management of recurrent aphthous stomatitis (ras) in comparison with dapsone. Saudi Med J. 2008;29(5):734-8. Available at: http://www.ncbi.nlm.nih. gov/pubmed/18454224 PMID:18454224 